\title{
Improving Architectural Pedagogy toward Better Archistructural Design Values
}

\author{
By Sawsan Saridar Masri*
}

\begin{abstract}
"... Structure is columnar, planar, or a combination of these which a designer can intentionally use to reinforce or realize ideas. In this context, columns, walls and beams can be thought of in terms of concepts of frequency, pattern, simplicity, regularity, randomness and complexity..." Since earlier urban settlements; buildings, structures and monuments have revealed the work of the master builders who reacted to the social, political and religious needs of their age with their aesthetic creativity on one hand and the technical excellence on the other. Today, while architects regret the inhumanity and formality of structural engineers towards timeless values in architecture such as aesthetics, structural engineers criticize the architects for their lack of essential structural engineering knowledge. This research aims to improve the pedagogy of the architectural design studio along with efficient structural and technical content of the curriculum delivered to architecture students, for a better integration of architectural concepts with structural solutions. Architecture programs at Lebanese universities have been selected as a case study where program content, instruction approaches and teaching methods of structural subjects are examined, as well as students' performance and perception in integrating technical knowledge in their design projects. This selection has been due to a primary hypothesis indicating that some amendments are required. The study investigated that students show difficulties to integrate structural strategies with architectural decisions, and most of structural and technical courses have pathetic standing accompanied by student loss of interest and enthusiasm.
\end{abstract}

\section{Introduction}

The most renowned slogan formulated for the fundamental keywords defining architectural values is Vitruvius's famous triad of utilitas (function, commodity, utility), firmitas (solidity, materiality?), and venustas (beauty, delight, desire $)^{1}$. Each of the three corners in the Vitruvian triad is dependent upon the other two to form architecture, and all are vital in the creation of architectural quality to form architecture. Each component sets up different demands and principles that must be met in the architecture, and the interaction of the three corners creates a unity. Throughout the centuries, other concepts appeared within the discourse of architecture profession, and hence according to Hilary French 'architecture is not considered a self-sufficient profession anymore but a multidisciplinary, multi-skilled and multidirectional profession, $^{2}$ as shown in Figure 1. The argument here is that architecture is

\footnotetext{
*Assistant Professor, Beirut Arab University, Lebanon.

1. "The Vitruvian Virtues of Architecture: Utilitas, Firmitas, Venustas," online article, 1.

2. Hilary French, Architecture: a Crash Course (New York: Simon \& Schuster Ltd., 1998), 5.
} 
complex and there is no particular form of knowledge which appropriately describes it.

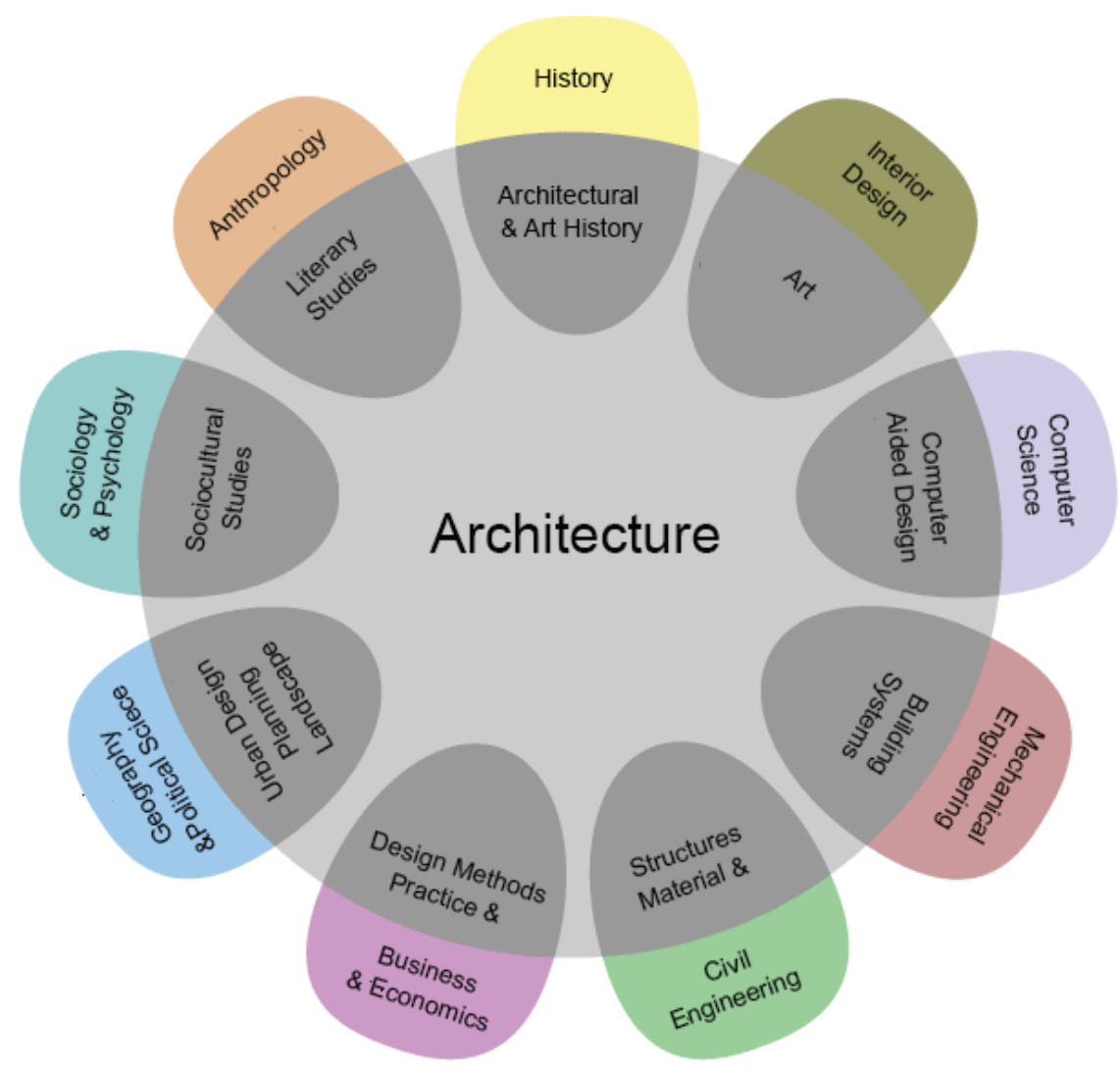

Figure 1. The Relationship of Architecture to Other Disciplines ${ }^{3}$

On the other hand, there are a number of international organizations such as the UIA (International Union of Architects), NAAB (National Architectural Accrediting Board of North America) and RIBA (Royal Institute of British Architects) which issue charters for architectural education. The UIA recommends that 'architectural education should ensure that all graduates have knowledge and ability in architectural design, including technical systems and requirements as well as consideration of health, safety, and ecological balance $^{, 4}$. The UIA particularly recommends that architectural education includes the acquisition of the following competencies: design, skill and knowledge; where knowledge should cover cultural and artistic studies, social studies, environmental studies, design studies, professional studies and technical studies. The NAAB establishes student performance criteria organized into four different realms: critical thinking and representation,

3. Adopted from Julia W. Robinson, "The Form and Structure of Architectural Knowledge: from Practice to Discipline," In The Discipline of Architecture, ed. Andrzej Piotrowski and Julia W. Robinson, 61-82 (Minneapolis: University of Minnesota Press, 2001), 70.

4. UIA-International Union of Architects, UIA Accord on Recommended International Standards of Professionalism in Architectural Practice (Paris: UIA Professional Practice Program Joint Secreteriat, 2014), 9. 
integrated building practices, technical skills and knowledge, professional practice, and integrated architectural solutions ${ }^{5}$. Similar criteria are also addressed in thee RIBA eleven general criteria and graduate attributes. ${ }^{6}$

The aim of this research is to examine whether the knowledge and skills acquired in Structural Design and Analysis, and Building Construction Technology modules taught to undergraduate architecture students are transferred into their studio work. It also seeks to identify how amendments to the teaching methods and course delivery can reinforce this relationship.

\section{Methodology}

This research adopts an inductive methodology, whereby it starts with a limited definition of the problem, and as the work proceeds a clearer perspective is identified. As the research progresses into the diagnostic steps (or survey) new parameters and factors are revealed and the multiplicity of challenges unfolds. These are then taken into consideration and incorporated into a full standpoint and orientation to develop the pedagogical approach with viable solutions and guidelines.

The first part of this study constitutes a theoretical discourse that attempts to generalize the approaches embraced by diverse schools of architecture, and best-practice recommended in educational institutes universally.

The later part of this study reviews the case of Lebanon as a vehicle to test these views on a pragmatic level. In general, this multi-step methodology is envisaged to help in better addressing a local educational context with its precise nature and particular circumstances. It develops intensive knowledge about complex field of Architectural education in Lebanon. Its aim is to describe and examine the composite local context, and in that sense what elements it comprises, the relations among these elements, and the overall impacts and influences. It presents useful information and a cross examination specific to the particular case of Lebanon, rather than information to generalize upon. This would be of great significance in formulating adequate guidelines and strategies for all groups locally involved in the pedagogical practices as well as for the policy-makers in charge. These notions are either suggested by experiences elsewhere, or derived from more comprehensive theory.

\section{Literature Review}

The knowledge and skills defined above managed to control the architectural design process. The architectural design studio which is the core subject acts as the learning platform where the knowledge of all other subjects

5. NAAB, Conditions for Accreditation (Washington: National Architectural Accrediting Board, 2014).

6. RIBA, RIBA procedures for validation and and validation criteria for UK and international courses and examinations in architecture (London: RIBA, 2014). 
should be incorporated. However, despite its recognized virtues, studio teaching is not sufficient to cover all the domains of knowledge offered in parallel to studios, such as history, theory, structures, technical issues, environmental science, economics, etc. Studio teaching exemplifies only the vision and values of the conceptual designer. With reference to the UIA guidelines concerning the value of architecture enhancing the quality of life, the indicators of architecture value defining the quality of a building vary between three categories; one depending on the mainly subjective character of the assessment, and the other two categories depending on objective criteria of assessment and the capacity to measure, calculate or estimate objectively and scientifically its performance. ${ }^{7}$ These parameters are clearly identified in Figure 2.

Despite the fact that technical value (including structural stability and safety in construction) has objective criteria of analysis and its assessment is based on measurement and calculation, the integration problems of such knowledge in design studios remain because of the tension between creative thinking and scientific aspects. The problem is further provoked by structure courses in most of the architectural schools where:

- Students put great effort to understand statics, and with applying mathematical measures to solve structural problems;

- There is insufficient time to teach statically undefined structural systems that are more complex than simple beams and columns;

- There is an apparent separation between design studio and structure courses.

Accordingly, in architecture design studio there is a need to enable a maximum creativity through the knowledge of all disciplines involved. This may be achieved by the adoption of interdisciplinary and transdisciplinary mode of learning, opposed to intradisciplinary and multidisciplinary mode, where creative design is considered within a single discipline without taking into account any criteria of other discipline. As shown in Table 1, four learning modes are defined according to the types and levels of interactivity between disciplines. In consideration of different types of interactivity, the concept of each learning mode is expected to be applied identifying the identity of students and teachers. ${ }^{8}$

7. Adopted from the UIA-International Union of Architects, UIA Guideline Concerning the Value of Architecture Enhancing the Quality of Life (Paris: International Union of Architects, 2015), 9-13.

8. Ji-Yong Park and Jeong-Bae Son, "Transitioning toward Transdisciplinary Learning in a Multidisciplinary Environment," in International Journal of Pedagogies and Learning 6, no. 1 (2010: 82-93), 85. 


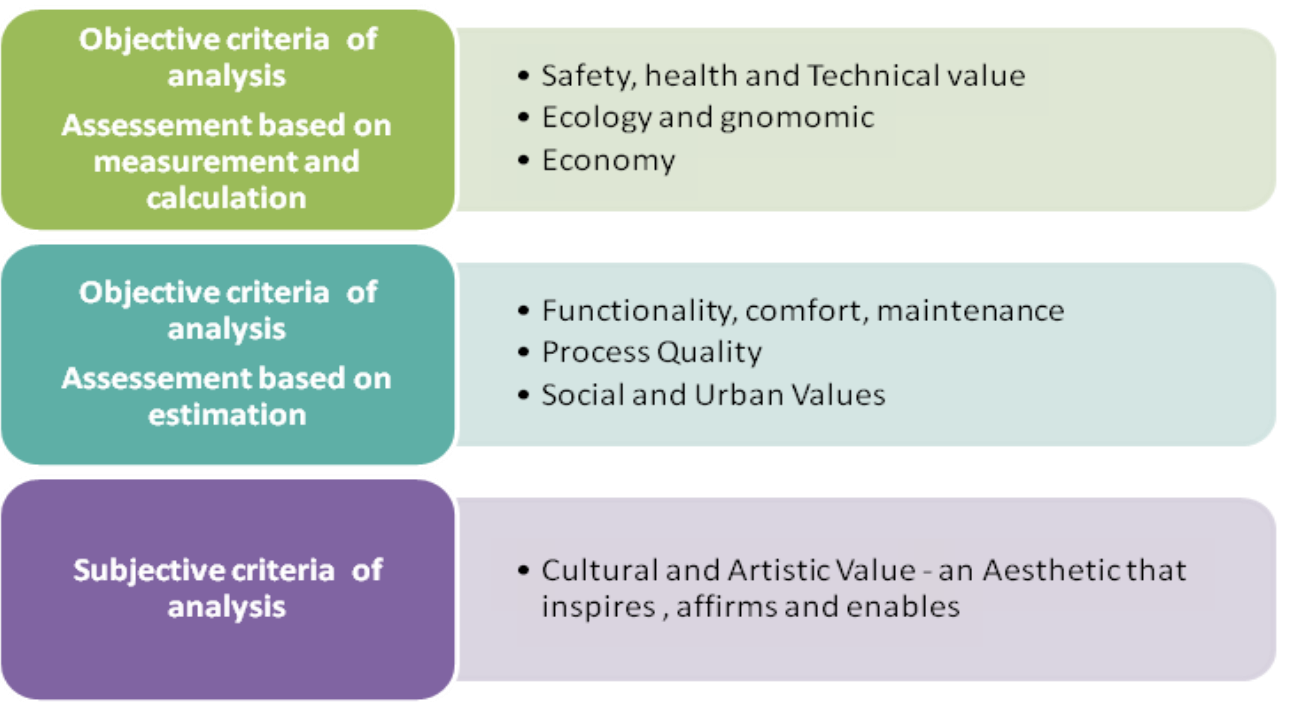

Figure 2. Parameters Defining the Quality of Building/Architecture and Associated Method of Assessment ${ }^{9}$

Table 1. The Difference between Different Learning Modes and Associated Interactivity between Disciplines ${ }^{10}$

\begin{tabular}{|c|c|c|c|}
\hline Learning Mode & Interactivity & $\begin{array}{l}\text { Student } \\
\text { Identity }\end{array}$ & $\begin{array}{l}\text { Teacher } \\
\text { Identity }\end{array}$ \\
\hline \multicolumn{4}{|l|}{ Intradisciplinary } \\
\hline & $\begin{array}{l}\text { Topic Driven: } \\
\text { within arking } \\
\text { discipline. }\end{array}$ & $\begin{array}{l}\text { Knowledge } \\
\text { receiver }\end{array}$ & $\begin{array}{l}\text { Knowledge } \\
\text { deliverer }\end{array}$ \\
\hline Multidisciplinary & $\begin{array}{l}\text { Discipline to discipline } \\
\text { driven: people from } \\
\text { different disciplines } \\
\text { work jointly, each rely } \\
\text { on their disciplinary } \\
\text { knowledge. }\end{array}$ & $\begin{array}{l}\text { Knowledge } \\
\text { consumer }\end{array}$ & $\begin{array}{l}\text { Knowledge } \\
\text { facilitator }\end{array}$ \\
\hline Interdisciplinary & $\begin{array}{lr}\text { Learner collaboration } \\
\text { driven: integrate } \\
\text { knowledge and methods } \\
\text { from different } \\
\text { disciplines, using a real } \\
\text { synthesis of approaches. }\end{array}$ & $\begin{array}{l}\text { Knowledge } \\
\text { collaborator }\end{array}$ & $\begin{array}{l}\text { Learner } \\
\text { designer }\end{array}$ \\
\hline Transdisciplinary & $\begin{array}{l}\text { Learner participation } \\
\text { and new knowledge } \\
\text { creation } \\
\text { generate a unity of } \\
\text { intellectual frameworks } \\
\text { beyond the disciplinary } \\
\text { perspectives. }\end{array}$ & $\begin{array}{l}\text { Knowledge } \\
\text { producer }\end{array}$ & $\begin{array}{l}\text { Interactive } \\
\text { learning } \\
\text { designer }\end{array}$ \\
\hline
\end{tabular}

9. Ibid, 9-13.

10. Ibid, 85 . 


\section{Architecture Education in Lebanon}

The curriculum contents of professional degrees offered at Lebanese universities are analyzed highlighting the modules addressing architectural design studios, material and construction technologies, structural engineering and services systems. As shown in Figure 3, this analysis indicates that Design Studios, like most architecture programs worldwide, constitute more than 50\% of the curriculum; the 6-years postgraduate diploma at ALBA has the highest of $73 \%$ while the Bachelor of Architecture at MUT has the lowest percentage of $45 \%$. Modules addressing Construction technologies have different percentages in studied programs varying from $13.5 \%$ at BAU to $2.1 \%$ at USEK. As for the modules addressing knowledge in structural engineering, percentages varies from $1.7 \%$ at AUB to $8.2 \%$ at NDU. Knowledge of services systems also varies between $0.8 \%$ at ALBA and $8.2 \%$ at NDU. BAU, LU, and NDU are more distinguished in offering a higher percentage of technical studies.

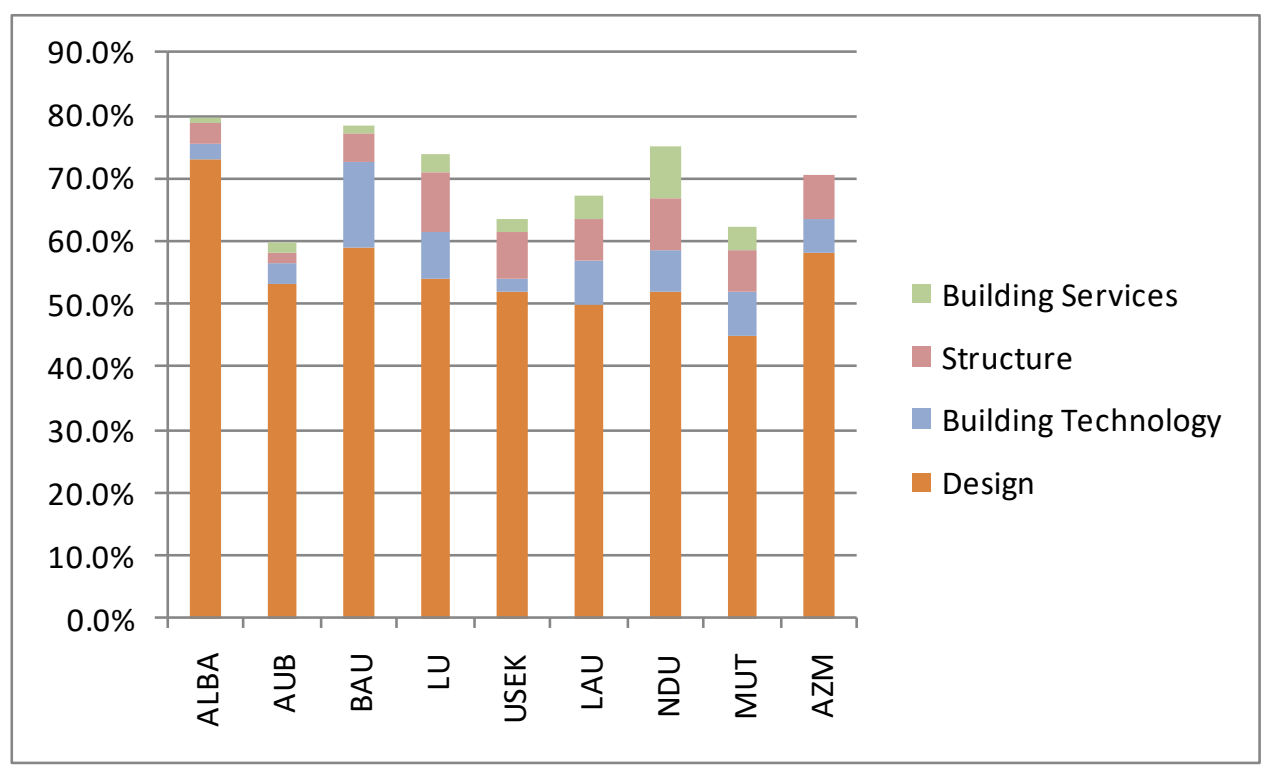

Figure 3. Analysis of Curriculum Content of Professional Degrees Offered at Lebanese Universities with Regard to Structural and Technological Knowledge $e^{11}$

As shown in Figure 4, Architecture students are firstly introduced to building technology and construction modules in their second or third semester while structural courses come later on as separated modules from architectural design. The design studio assignments require students to consider building structures in all projects. Level 1 and level 2 students may not confront notable complexity as their design projects are simple single or double storey building. The problem becomes more apparent at level 3 when design projects involve

11. Data extracted by the Researcher from the analysis of architecture curriculum content offered at diverse universities in Lebanon. 
buildings with multiple function spaces of wider spans that require a variety of structural loads. Students do not utilize the knowledge gained through lectures and stand-alone applications acquired from structure modules, where they are apparently unable to visualize their designs in relation to the mathematical formulas and calculations of such building loads, frames, cables, tension and compression trusses, and even the shearing forces and bending moment design of reinforced concrete. The current structure subjects fail, in terms of teaching method and content, to establish a clear liaison to design studio and do not motivate students to apply integrated structural design solution within their design projects.

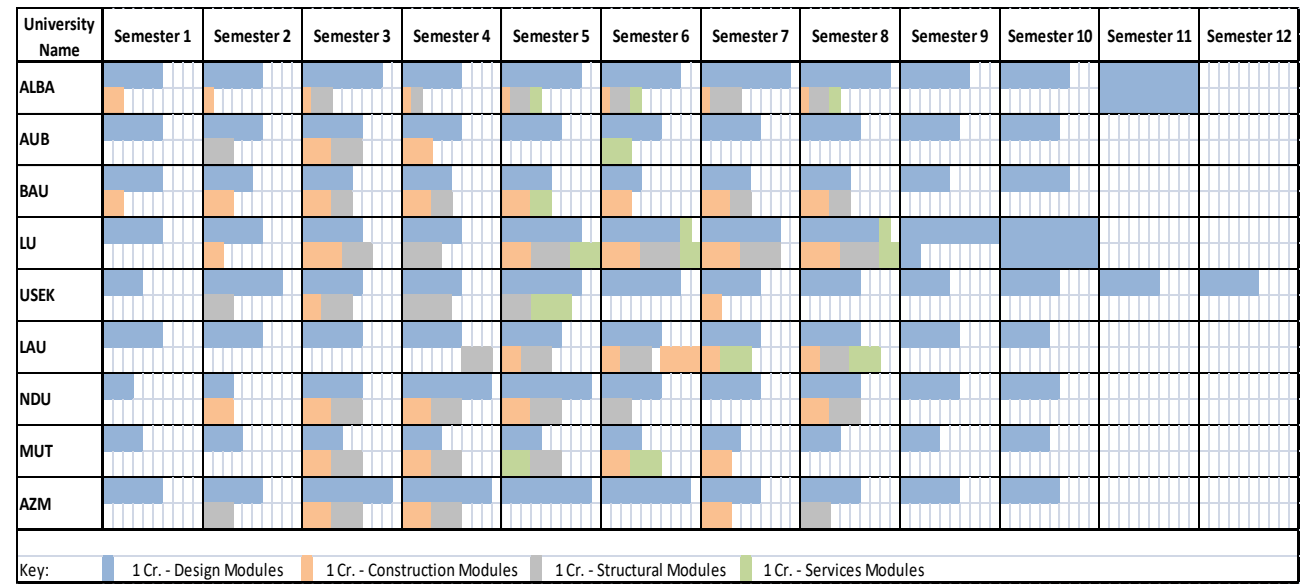

Figure 4. Distribution of Design, Building Technology, Structure and Building Services Courses over the Time Span of Architecture Programs Offered at Lebanese Universities ${ }^{12}$

Building technologies and construction knowledge is achieved throughout the second, third and fourth years as parallel courses with architectural design modules. The syllabus of such modules include building construction systems, building materials, building elements, detailing and construction systems, etc. After the knowledge of construction systems, students acquire knowledge and learn details about window, door, roof, wall floor, etc. All of these topics have to do with the real life practice. Despite the great amount of acquired knowledge about construction given to students, the problem remains how to integrate such knowledge to design processes. Students use not to think about details of the buildings during preliminary or even final design stages of design studio assignments. Indeed, working drawing and detailing come in a subsequent phase where students may be asked to develop execution drawings of their designed projects within distinct modules from the design studio. Consequently, comprehension of technical design processes and the integration of structure, construction technologies and services systems into a functionally efficient entity remains complicated to students.

12. Ibid. 


\section{Case Study and Analysis}

\section{Design Projects Emphasizing on Structural System}

The research focuses on the course objectives and method of teaching structure and the integration in design studio in the third year of architectural engineering at Beirut Arab University during the academic year 2014/2015. The integration of various subjects within the first module of $3^{\text {rd }}$ year design studio is strongly recommended, specifically structural and technological knowledge. Figure 5 illustrates samples of the third year design studio project submission at Beirut Arab University in Fall 2014. Students were asked to design an Information Pavilion within Beirut International Exhibition \& Leisure Center (BIEL). The aim of that project was to achieve the following:

- Develop design solutions which integrates function, structure, details and the qualities of internationality;

- Explore, meet to and bring up to light the exclusive design features of an information pavilion that will be used by visitors during any national and international Expo; and

- Promote sustainability to be used in all aspects in design proposal.

The illustrated samples confirm that students' ability to integrate structure components is not suitably reflected in conceptual design and practice. These drawings contain very little structural knowledge. It is a naïve representation of the shape of the structure with a very low level of abstraction; the plans and sections mainly convey 3D volumes or shapes, lacking calculations of structural elements dimensions that show little knowledge of the structural engineering discipline. In addition, most of the structural solutions selected by students for their projects are basic reinforced concrete in-situ post and beam concepts, or schematic steel frame or truss structural systems. The external façade design are made of any new 'stylish' façade materials, elements which are inspired from the latest design magazine, as additional features which in turn are not integrated with the whole structure of the building. The structural solution is therefore, complicated, misguided and generally confusing. Many of the structural proposals fail to establish a clear relationship with the conceptual design.

These cases have a typical intradisciplinary character; students design the architectural shape under the guidance of the studio instructors which are all architects. In addition, structures subjects regarded as fundamentals to the education of the architect are developed outside the architecture discipline and borrowed from engineering programs. Again an intradisciplinary approach is used in developing subject contents, methods and teaching tools. This has lead to students design project that lean greatly on forms and unproblematic structure solutions or may not state any structure integration at all in their design proposal. 

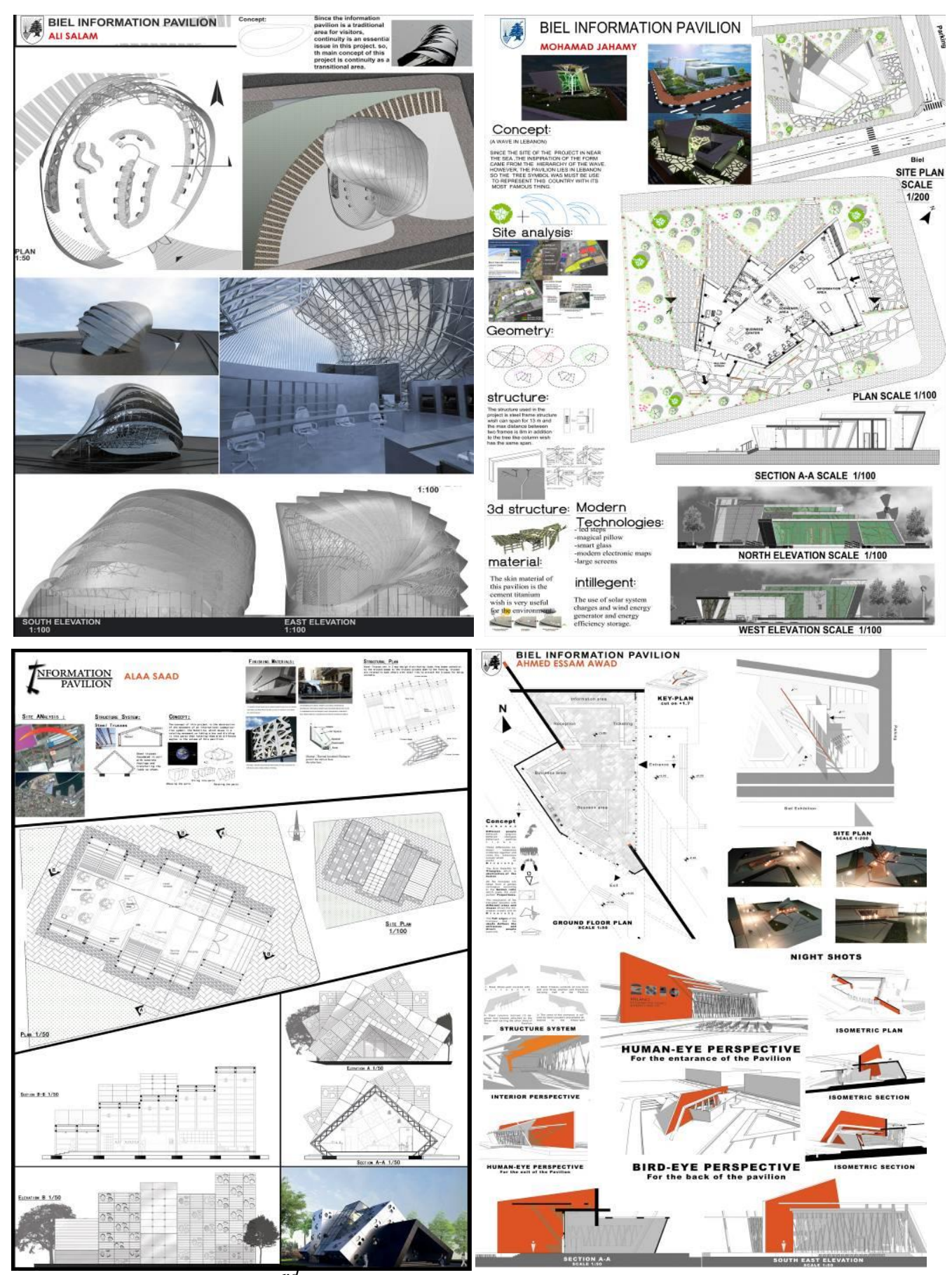

Figure 5. Samples of $3^{\text {rd }}$ Year sSudents' Work at Beirut Arab University (BAU) Illustrating a $300 \mathrm{~m}^{2}$ Universal Space Used as an Information Pavilion ${ }^{13}$

13. Taken from student sampling of 3 rd year design studio taught by the author in $2014 / 2015$. 
This is particularly clear in the selected sample projects illustrated in Figure 6 which are the second assignment given third year students in fall 2014. The students were requested to design a Researcher Guest House building. In this project, students have selected more conventional modular structural solutions' post and beam, and their structural analysis was just limited to the location of column and the selection of construction material. Students' knowledge of structural and technological issues remains constant with no further development.

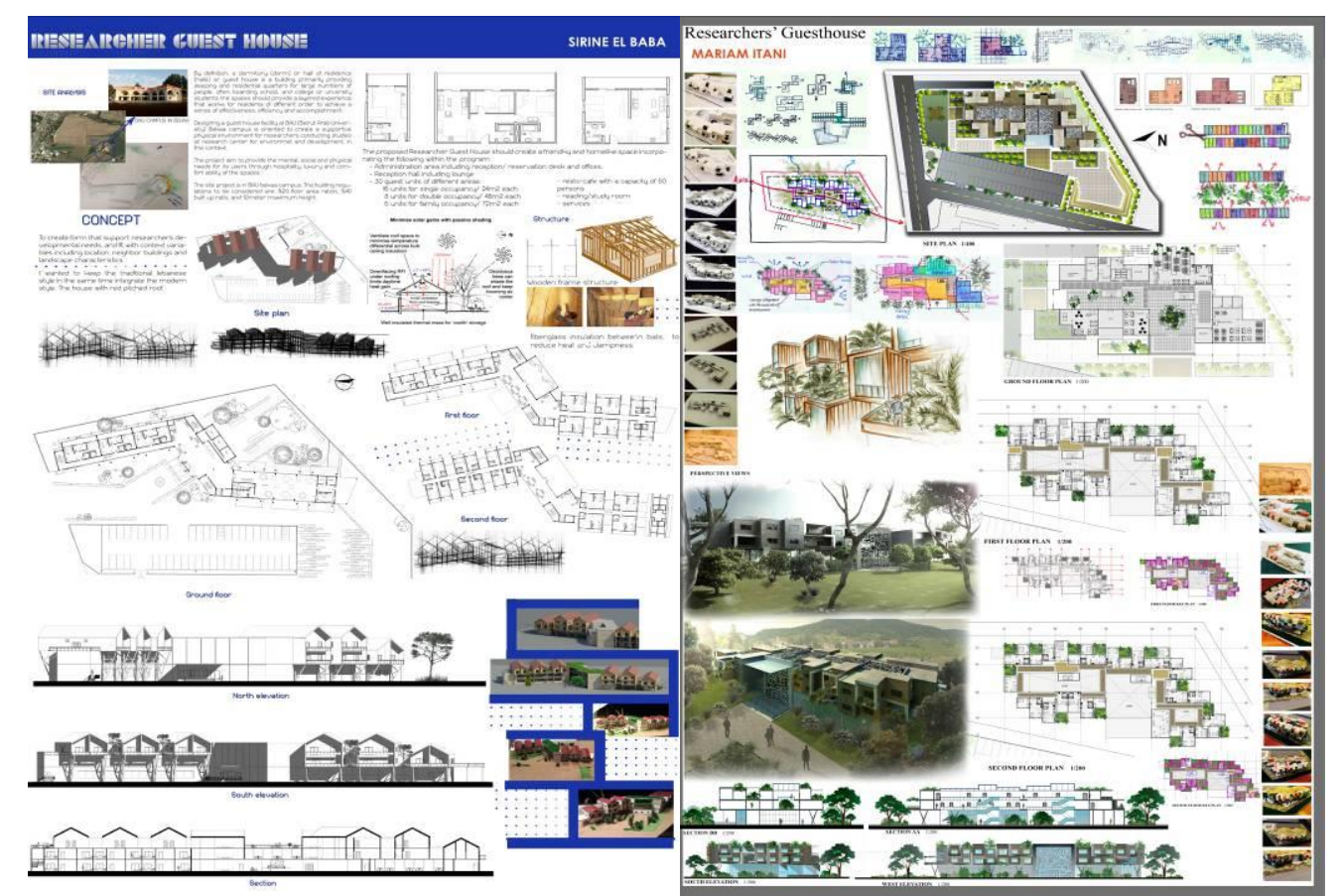

Figure 6. Samples of $3^{\text {rd }}$ Year Students' Work at Beirut Arab University (BAU) Illustrating Design Proposals of Researcher Guest House Building ${ }^{14}$

Students' Perception toward Integrated Design Studio

A total number of 50 questionnaires were handed to BAU architecture students from year 3 to year 5 as these students are supposedly completed almost all or most of structural and technical modules. This survey was carried out in May 2016. The questionnaire was designed to assess the students' awareness of their weakness on the structural understanding and poor integration of structure in their design projects. Students were asked about the method of design and studio progress where integration of technical and creative parts take place, in addition to questions related to their perception on the necessary architectural design knowledge, skills and competencies, the role of academic staff and criteria of assessment. The questionnaire included the following questions:

14. Ibid. 
1. Which architectural design approach do you prefer to achieve a successful design project?

2. What knowledge and skills are essential in architectural design?

3. What qualities are considered necessary to be proficient architectural student / architect?

4. How do you proceed to solve a design problem and develop an initial design concept?

5. What are the criteria considered by instructors during project follow up?

6. What are the criteria considered by the examiners during the final project assessment?

7. How often does design studio tutor put hands in with you in solving problems?

8. How do you evaluate the effect of named courses on design studios?

Each of the above questions had a number of standardized answers; the student's task was to evaluate each of these answers and specify their level of agreement or disagreement on a symmetric Likert scale of five. Each of them had an assigned numeric value with +2 being the most accepted and -2 the least rejected in order to calculate the sum for each answer. To be able to compare the answers each sum was divided by the number of respondents given for the specific standard answer.

Figure 7 illustrates the standardized answers of the first question asking students to specify the preferred design approach preferred to achieve a successful design project. 52\% of the respondents do not have a preferred approach; while 14\% think that starting with the design of the form followed by solving the problem of functionality and finally dealing with the structural issues lead them to achieve a successful design project (Figure 7). Another $14 \%$ of respondents prefer to solve the problem of form, function and structure in parallel. Only $4 \%$ of students consider structure as an initial approach in developing design concepts.

The following question in the questionnaire was about the knowledge and skills that are considered essentials for students in architectural design. Eight out of twelve standardized answers were approved by third and fourth year students while fifth year students approved only five; artistic skills, social and cultural issues, and knowledge of environmental and sustainable issues are considered less essentials for fifth year students (Figure 8). The most preferable answers were 'Knowledge of design process and methods' ( 1.40 to 1.55 points) and 'Computer skills' (1.30 to 1.45 points). On the other hand, 'Knowledge of Architecture History' ( 0.15 to 0.75 points) and 'Understanding of service systems' (0.55 to 0.90 points) gained little less acceptance. Concerning the 'Technical knowledge of structure, materials, and construction technologies', students of all levels agreed on the importance of this knowledge in architectural design (1.00 to 1.15 points) (Figure 9). 


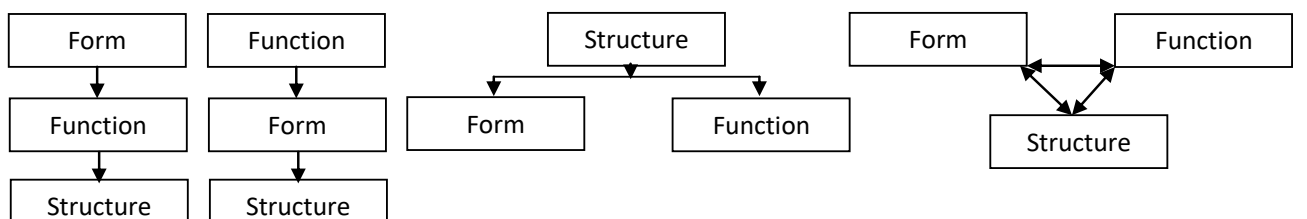

Figure 7. Standardized Answers of Design Approach Preferred by Respondents to Achieve a Successful Design Project ${ }^{15}$

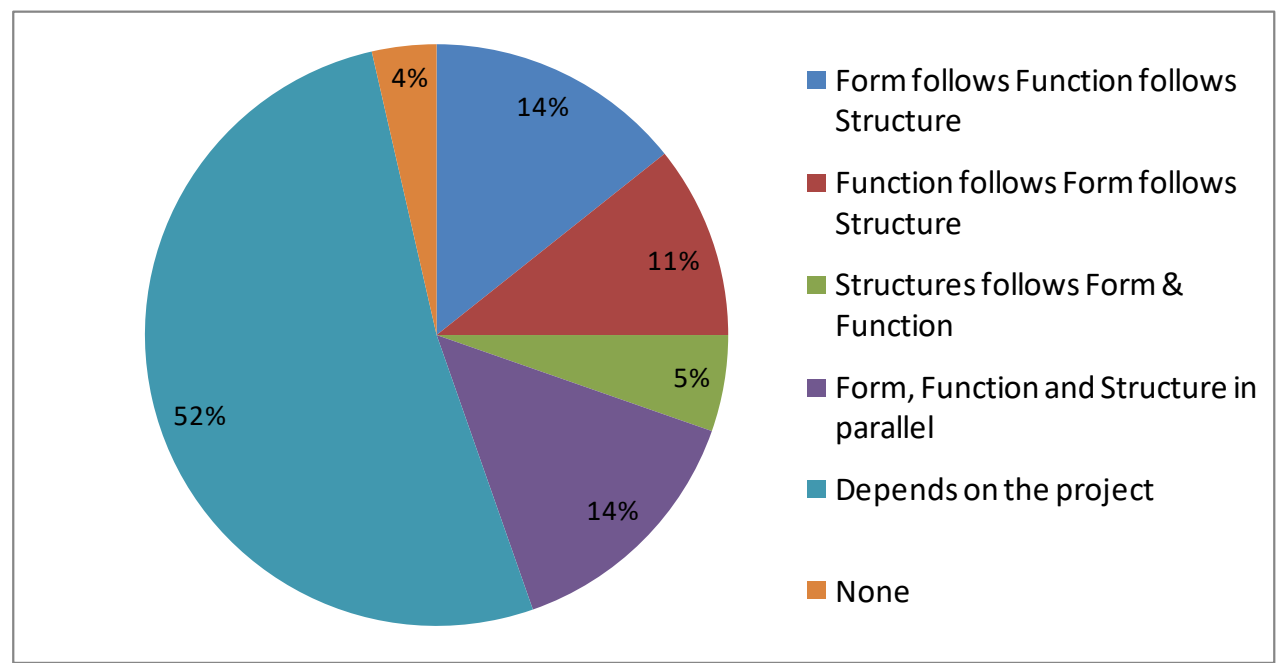

Figure 8. Students' Preference of Design Approach ${ }^{16}$

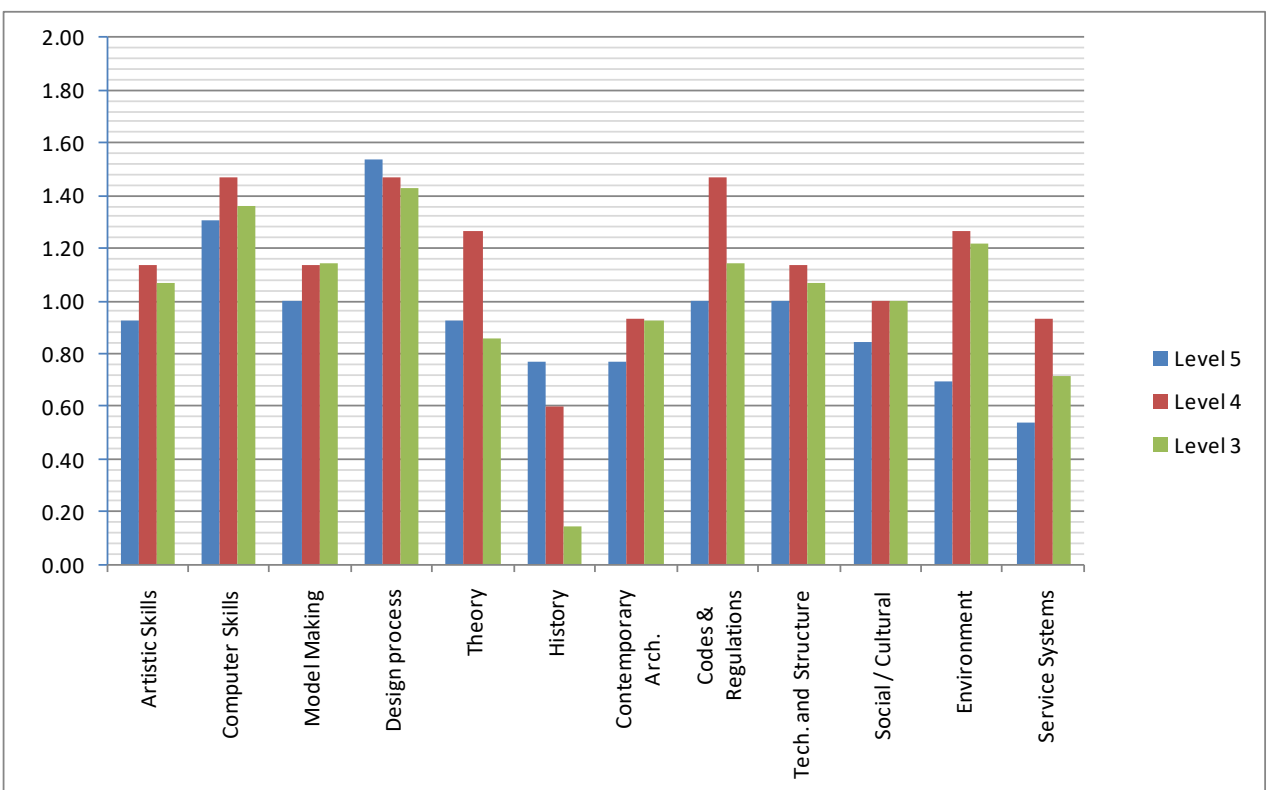

Figure 9. Knowledge and Skills Essential in Architectural Design. ${ }^{17}$

15. The standard answer of the first question from the questionnaire designed and conducted by the author in May 2016.

16. Analysis of the survey conducted by the author in May 2016.

17. Ibid. 
All suggested answers to the question about the qualities and competencies that are considered necessary to be talented architecture student / architect have been evaluated positively by all students of different levels, except one out of ten which 'Artistic talent' (Figure 10). That means that most students do not consider architecture as pure art. The necessity of 'Motivation' (1.30 to 1.75 points) and 'Communication skills' varies increasingly between third, fourth and fifth years; both qualities become more significant during the study period (1.35 to 1.70 points).

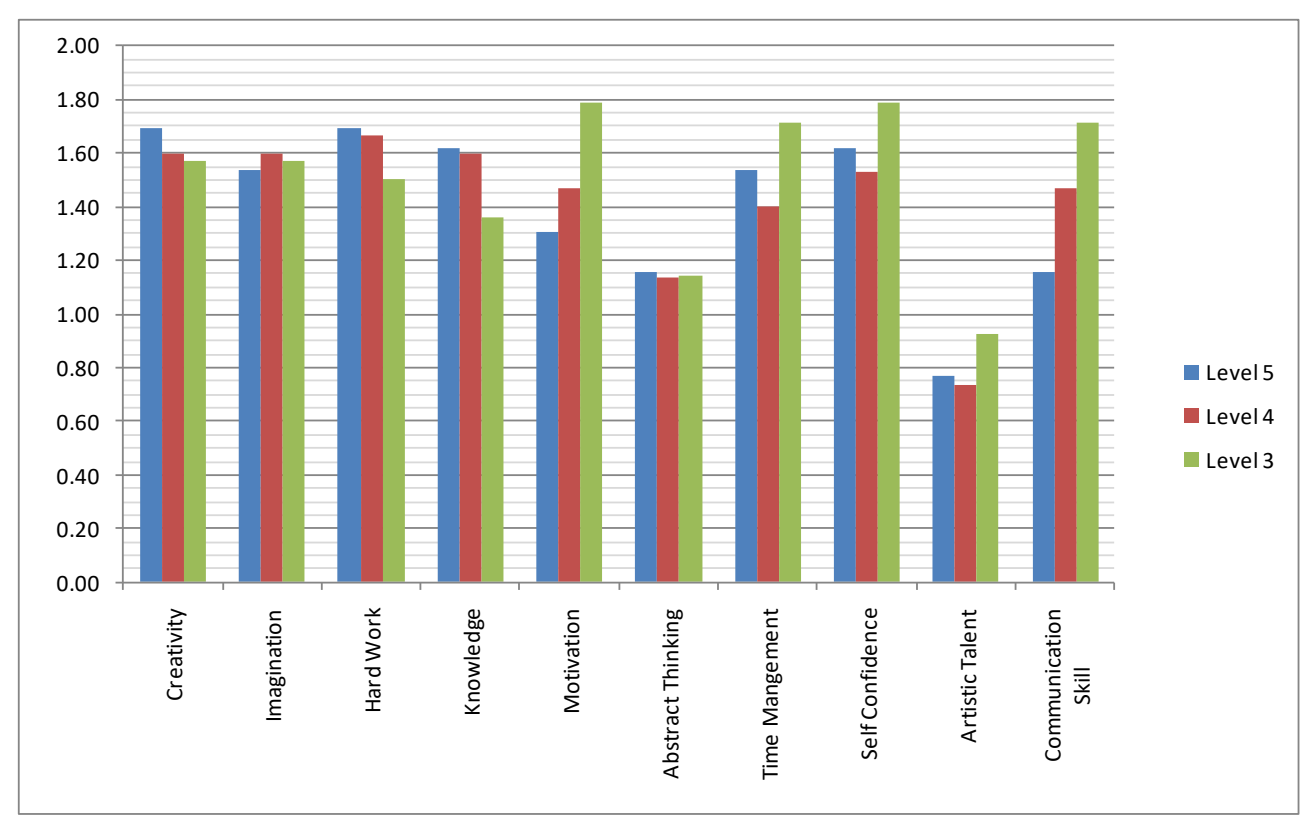

Figure 10. Qualities and Competencies Necessary for a Proficient to Student/ Architect $^{18}$

The next question was related to the methods brought into play while developing initial design concept, and the ways in which students proceed to solve a design problem (Figure 11). Responses varied extensively between students of different levels, but the mostly accepted methods are 'contextual analysis ( 0.85 to 1.55 point), 'analysis of similar examples' (1.00 to 1.50 points), 'functional analysis' (1.25 to 1.35 point), 'formative approach' (1.00 to 1.25 points), and environmental approach (1.00 to 1.25 points). This indicates that students develop various design methods throughout their period of study. It is important to indicate that constructive approach becomes less addressed while students advance in their study and less stress is put on structural and technical values.

18. Ibid. 


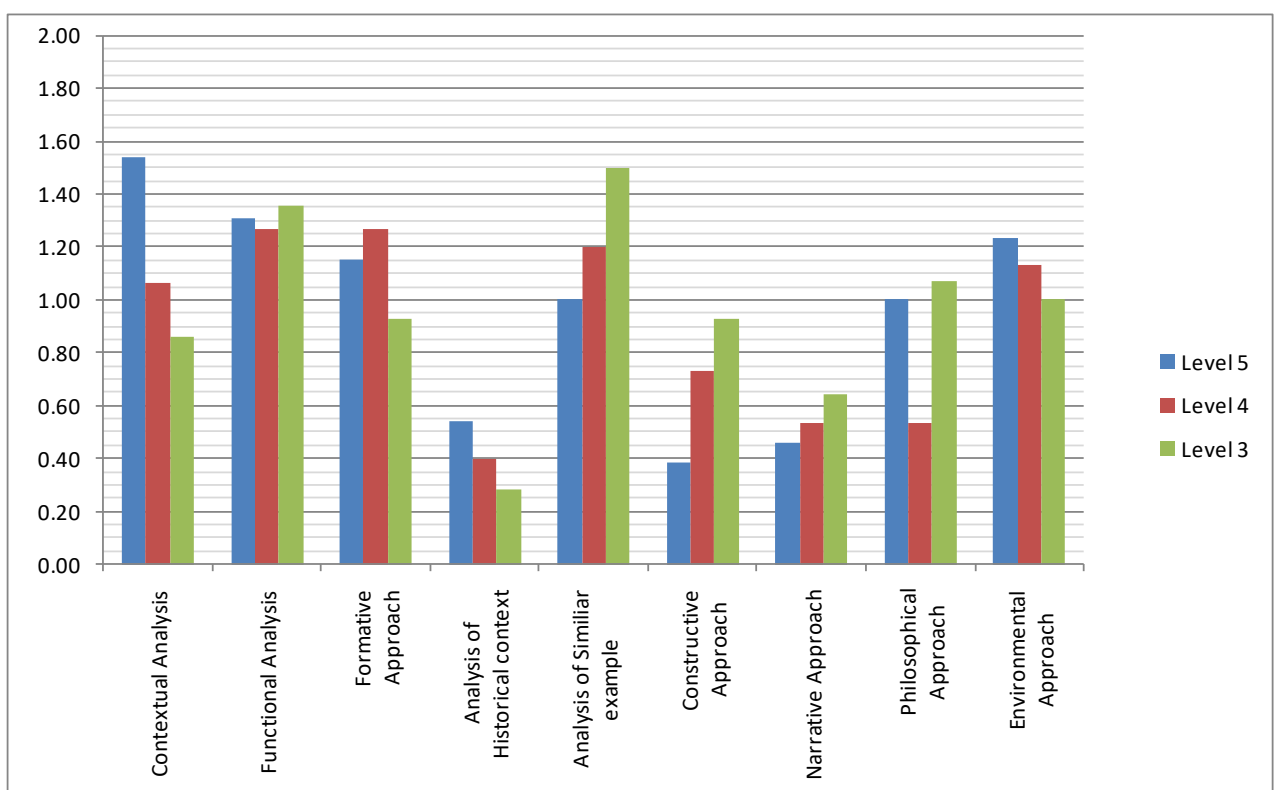

Figure 11. Methods of Solving Design Problem and Developing Initial Design Concept $^{19}$

The following two questions were to define decisive factors in assessing architectural projects during the following up and final examination. There were eight answers to these two questions. Figure 12 and Figure 13 show that the assessment criteria adopted and considered during the follow up of design development are different from the ones considered during the final examination. However, structural and technical correctness, contextual consideration, and compliance with rules are thought to be the least considered in all assessments. Structural and technical correctness is thought to be mostly considered in $3^{\text {rd }}$ year assessments and the least $5^{\text {th }}$ year assessments. On the other hand, completeness of design is believed to be mostly considered during final assessment; this controversial answer affirms that students do not have a clear understanding of 'project completeness' and what a 'holistic design' should encompass.

The following question was to determine the students' expectations toward the student-tutor relation and in what the tutors help the students to solve design problems (Figure 14). The only answer that gained acceptance of students at all levels is 'functional requirement and spatial relationship' (1.20 to 1.40 points), and 'building form' was accepted by both fourth and fifth year students only. All other six answers were all rejected by all students. This result signifies that the design tutors and students fail to integrate the knowledge acquired from other modules in the design studio. Regarding the help students get in solving problems related to structural system and technical issues, students think that the support they got is not often.

19. Ibid. 


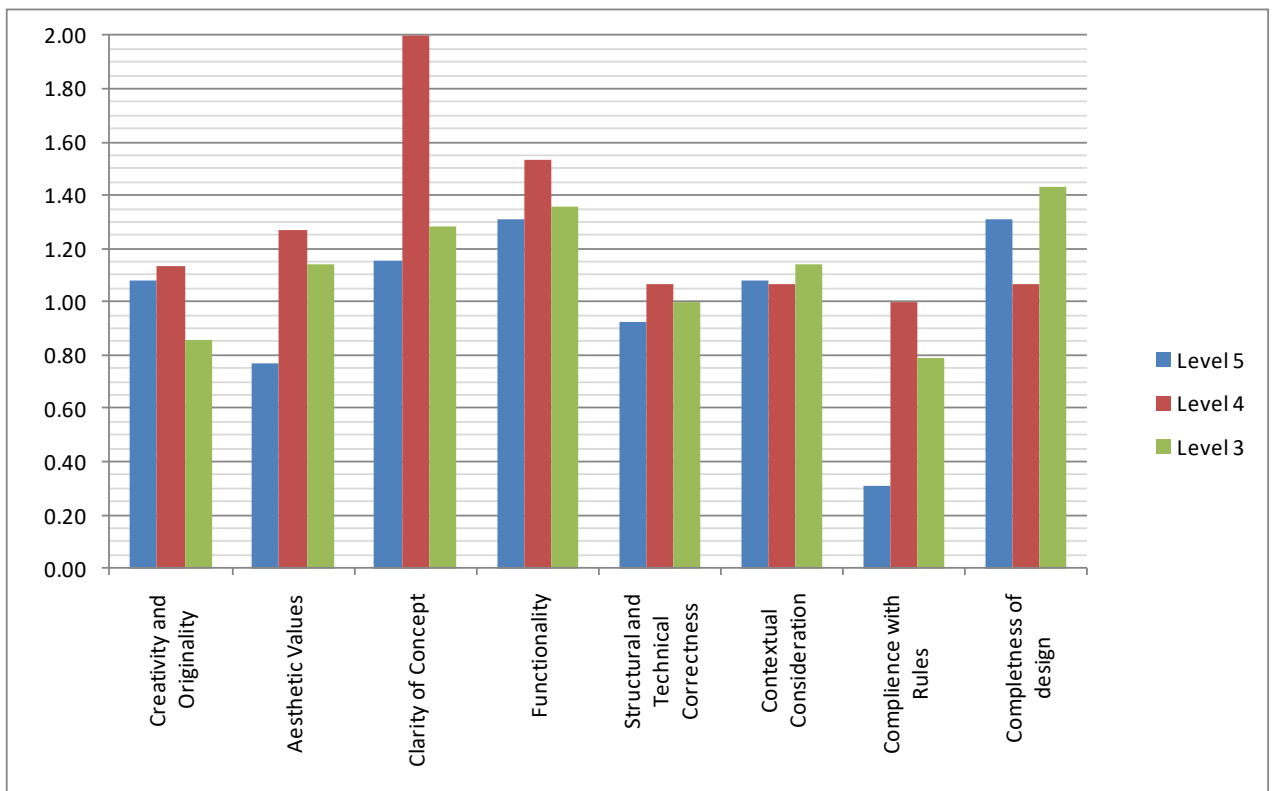

Figure 12. Assessment Criteria Considered by Instructors during Project Follow up ${ }^{20}$

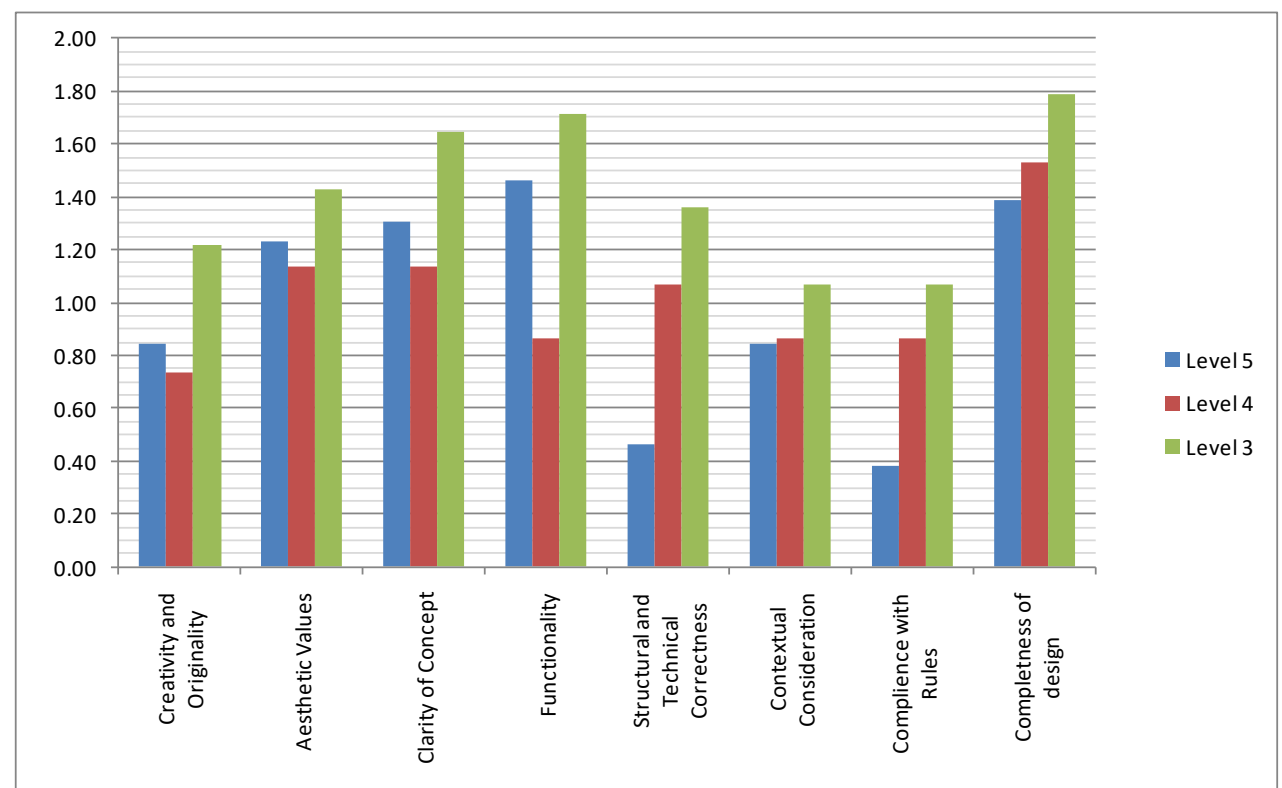

Figure 13. Assessment Criteria Considered by Examiners during Final Project Assessment ${ }^{21}$

20. Ibid.

21. Ibid. 


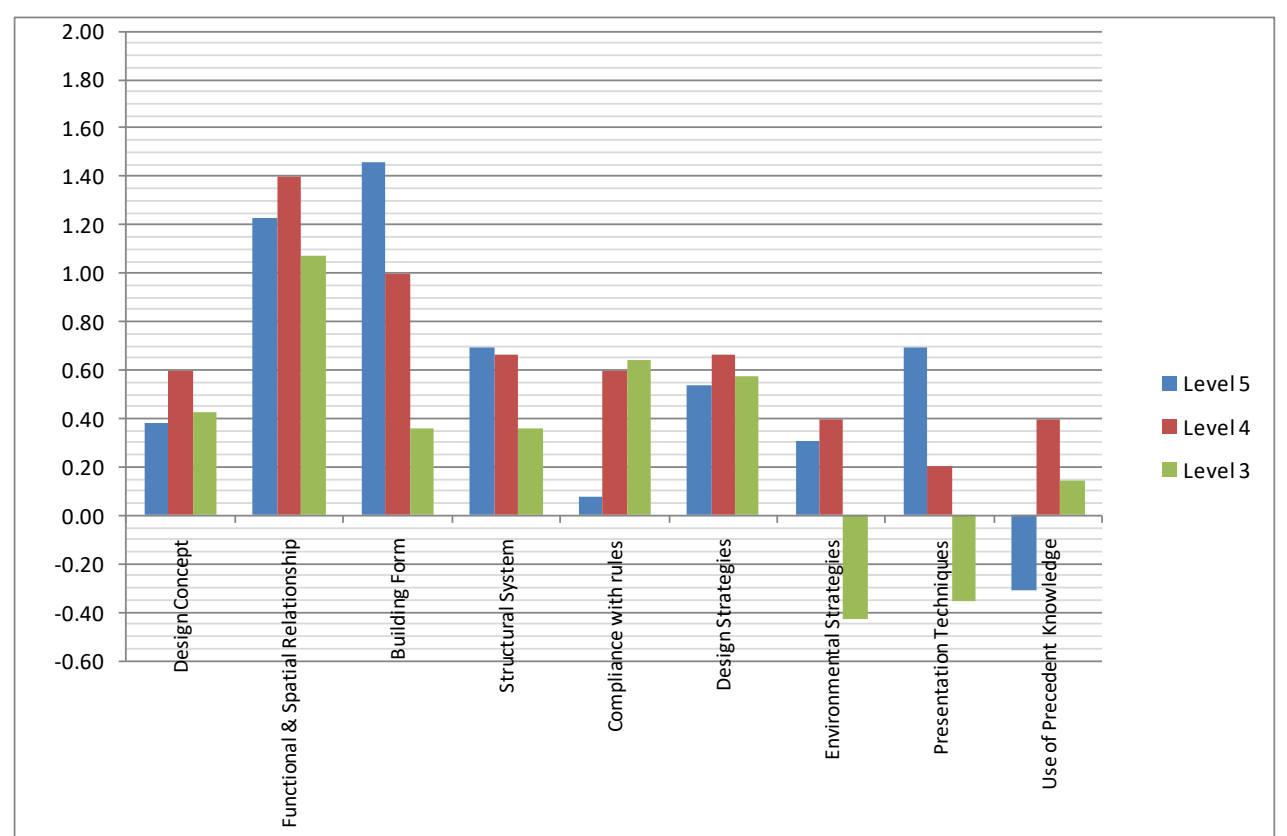

Figure 14. Role of Design Studio Tutors in Helping Students to Solve Design Problems $^{22}$

The last question in the questionnaire, students were asked to evaluate the effect of taught courses related to structural and technical issues (Figure 15). Students think that only building construction modules taught in the first and second years, and execution design modules taught in the third and forth level are helpful. On the other hands, students are not able to find any support from structural modules they have studied to architecture design studio as structure course content emphasizes more on the structural mechanics rather than structural behavior. A student commented saying: "Teaching of structural and technical courses should work in parallel with the design studio in order to feel its implementation in our projects". Another student stated that "Please remember the ONE BOAT shipping; now students and staff are in a broken boat. They should be both on the same boat". This means that the multidisciplinary in teaching architecture design studio fail to deliver a holistic approach in solving design problems. To take the same boat, trans-disciplinary approach is therefore recommended. Tutors of different disciplines and expertise should contribute positively in developing the knowledge and skills of students in solving design problems holistically.

22. Ibid. 


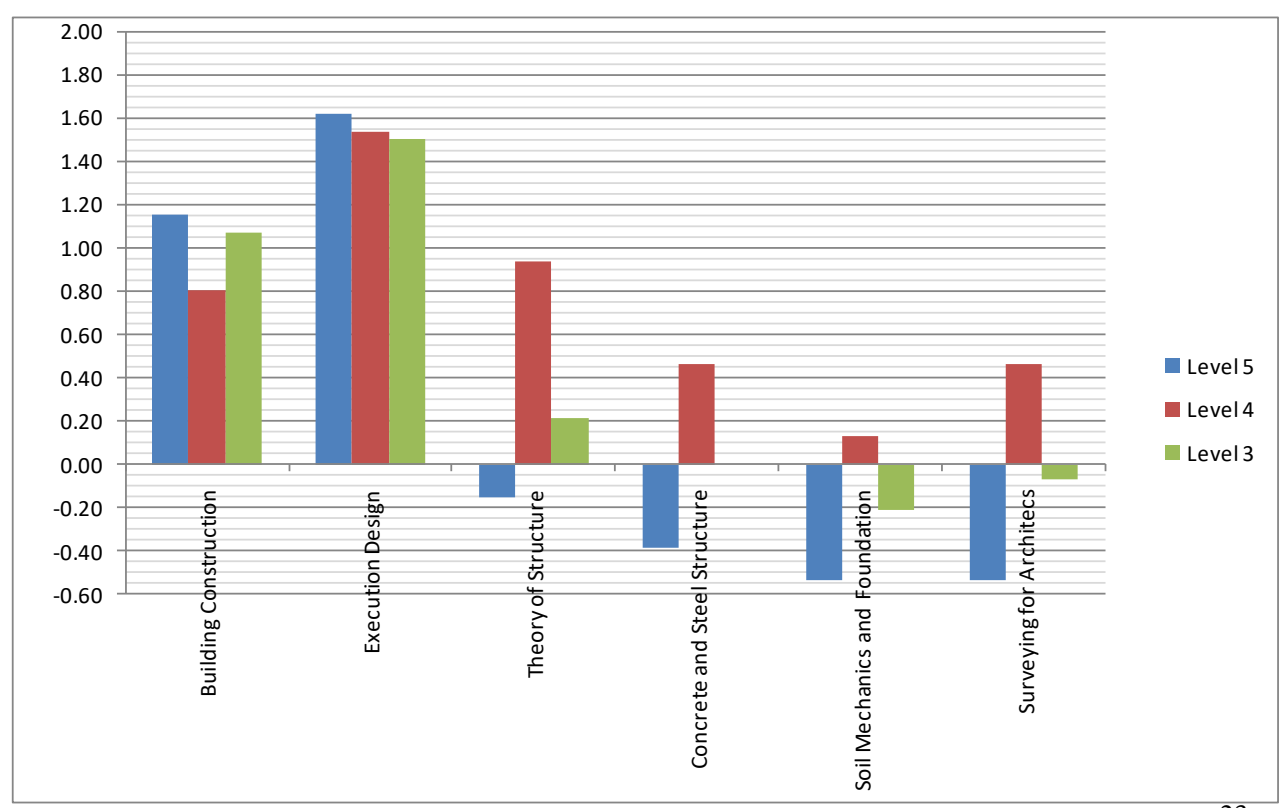

Figure 15. Effect of Structural and Technical Modules on Design Studio ${ }^{23}$

\section{Conclusions}

The design studio is the core subject of the architectural education. Therefore, it is greatly recommended that assigned coursework of parallel modules to be cross-referenced with design modules, particularly structural and technical courses in order to improve the student's conception of a holistic design. Dealing with the problem of structure at an early stage of the design, the student would have a better ability to integrate the structural with architectural design elements and provide a most appropriate scheme for the building construction system. To create interest in structure and technology of buildings, the student would have a variety of inspirations to develop more creative design solutions. In addition, students would experience interdisciplinary learning and working environment.

Architecture students have conventionally been taught structural design using an engineering-based learning replica. Information is presented in terms of mathematical formulas with abstract description of the architectural space. In other words, the structural design is presented as a sequence of calculations instead of a series of design sketches and drawings. Therefore, a new pedagogical model for teaching structural design to architects is needed. Beginning students should be given a series of exercises that alleviate their understanding about the relationship between architectural form and structural forces and behavior. An example of such exercise could be the exploration of basic structural principles in the human body at different acrobatic movements. Bio-inspirational structures could be another model for teaching structural

23. Ibid. 
forms and analysis to architecture students. These sorts of applications will be tested by the researcher in future researches.

The question regarding knowledge and skills needed in architectural design draws attention to a very high rating of the computer skills. The ability to use a computer is already (according to the students) more valuable than knowledge of the methodology and design strategies, knowledge of the history and theory of architecture. The computer interest may be a serious indicator of the growing role of computer sciences in architecture. Nevertheless, while students seem more sophisticated in their attitude to learning how to use new digital programs, the need and desire to understand basic structural design concepts and theories remain virtually unchanged. As stated by William J. Mitchell: "Architecture is no longer simply the play of masses in light. It now embraces the play of digital information in space" ${ }^{24}$, instructors may need to inspect computer software to bridge the gap between architecture values and structural concerns, and find how to raise interest in the subject of structure by using virtual software. It is suggested to integrate intelligent 3D model-based process (BIM); thus, the subsequent questions are at which level BIM should be included and would BIM affect student's creativity?

Architecture students after graduation have to communicate with engineers; when architect and engineer design the architectural and the structural form jointly as an interdisciplinary team, they have to communicate. Their communication will only be successful if they have the same 'system of thoughts' (internal) and understand the same 'system of symbols' on this mutual ground of structural and architectural knowledge ${ }^{25}$. In other words, both architects and engineers must have mutual interdisciplinary knowledge (MIK). So the next question is: what should architect know about engineering, and engineers about architecture?

A reflection should be made about the educator; the role and identity of design studio tutors are much more valuable than being a technical proficiency and a designer 'debugger'. Who are the members (or disciplines) to be included in an interactive learner design team to achieve a proficient, productive and creative design studio environment?

\section{Bibliography}

Clark, Roger and Micheal Pause. Precedents in Architecture: Analytic Diagrams, Formative Ideas, and Partis. $3^{\text {rd }}$ Edition. New Jersey: John Wiley and Sons, 2005.

French, Hilary. Architecture: a Crash Course. New York: Simon \& Schuster Ltd., 1998.

Luyten, Laurens. "Communication between architect and engineer in a creative environment: A glimpse of the mutual knowledge required for interdisciplinary design.” 2009. http://bit.ly/2efEh81. [Accessed May 15, 2016].

24. William J. Mitchell, e-topia: Urban Life, Jim - But Not as We Know It (Cambridge: MIT Press, 1999), 280.

25. Laurens Luyten, Communication between architect and engineer in a creative environment: A glimpse of the mutual knowledge required for interdisciplinary design (2009), 2. 
Mitchell, William J. e-topia: Urban Life, Jim - But Not as We Know It. Cambridge: MIT Press, 1999.

NAAB-National Architectural Accrediting Board of North America. 2014 Conditions for Accreditation. Washington: National Architectural Accrediting Board, 2014.

Park, Ji-Yong and Jeong-Bae Son. "Transitioning toward Transdisciplinary Learning in a Multidisciplinary Environment." International Journal of Pedagogies and Learning 6, no. 1 (2010): 82-93.

RIBA-Royal Institute of British Architects. RIBA procedures for validation and and validation criteria for UK and international courses and examinations in architecture. London: RIBA, 2014.

Robinson, Julia W. "The Form and Structure of Architectural Knowledge: from Practice to Discipline." In The Discipline of Architecture. Edited by Andrzej Piotrowski and Julia W. Robinson. Minneapolis: University of Minnesota Press, 2001: 61-82.

"The Vitruvian Virtues of Architecture: Utilitas, Firmitas, Venustas." http://art3idea. psu.edu/locus/vitruvius2.pdf. [Accessed May 25, 2016].

UIA-International Union of Architects. UIA Accord on Recommended International Standards of Professionalism in Architectural Practice. Paris: UIA Professional Practice Program Joint Secreteriat, 2014.

UIA-International Union of Architects. UIA Guideline Concerning the Value of Architecture Enhancing the Quality of Life. Paris: International Union of Architects, 2015. 
